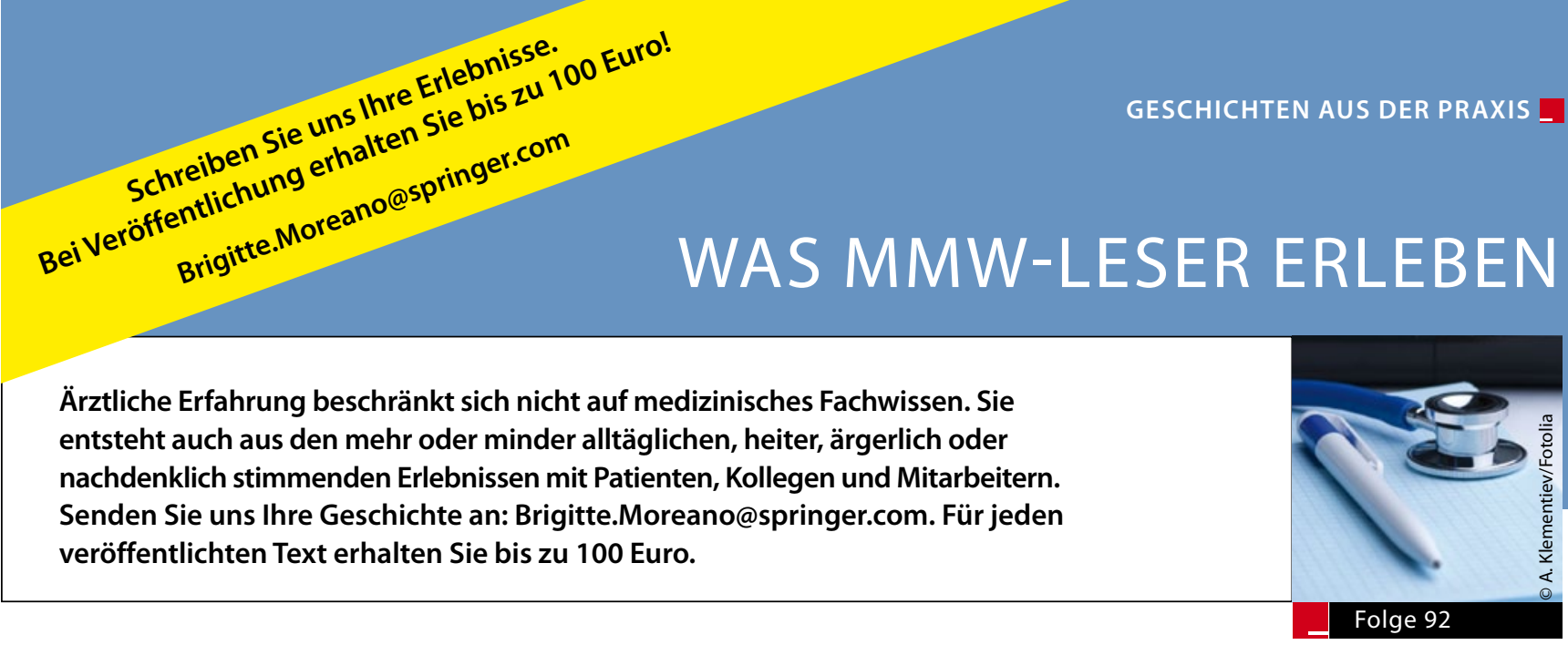

\title{
Lyrische Sprechstunde
}

- Ein junger Krankengymnast, der aber schon ewig mein Patient ist, war stark erkältet und sprach: „Ich bitte Sie um drei Tage Zeit ..." „Bis ich die Schwester dem Gatten gefreit..." kam meine spontane Antwort und: „Na, wie geht's denn weiter?".

Der Patient sah mich völlig irritiert an, woraufhin ich meinen in greifbarer Nähe stehenden „Ewigen Brunnen - ein Hausbuch deutscher Dichtung" zückte und Friedrich Schillers „Bürgschaft" vorlas, ganz und mit großem Pathos.
„.... ich lasse den Freund dir als Bürgen ihn magst du, entrinn 'ich erwürgen."

"Auf Wiedersehen und wenn Sie wieder kommen, dann tragen Sie mir die Ballade auswendig vor."

Als er nach drei Tagen zur Befundkontrolle erschien (...,und die Sonne geht unter da steht er am Tor ... da bin ich ...") erzählte er mir von seiner neuen Freundin, die ihn gefragt hatte: „Und was hat deine Ärztin gesagt?" "Ich soll die Bürgschaft von Friedrich Schiller auswendig lernen!!” Sie sei darüber aufs Äußerste verwundert gewesen und habe gefragt, ob ich denn wohl nicht richtig ticke? Dann hätten sie abends zusammen im Bett die Bürgschaft gelesen und beide wie die Schlosshunde geheult. Und nun wolle er einen Termin für seine Freundin haben.

Mein Kommentar: Er möge ihr bitte ausrichten: „Sie sei, ich gewähr' ihr die Bitte, in unserm Bunde die Dritte."

DR. MED. LUISE HESS, DARMSTADT •

\section{Der Gruß der asiatischen Katze}

- Eine meiner Patientinnen in Montpellier war eine sehr anspruchsvolle und sehr einsame alte Dame. Ihre wichtigste „Bezugsperson" war eine asiatische Katze, nicht einfach eine siamesische, sondern etwas viel Komplizierteres. Oft musste ich mir bei meinen Hausbesuchen den unendlich langen Stammbaum anhören. Diese Katze interessierte sich im Prinzip kein bisschen für mich. Jedenfalls bis zu dem Tag, als ich mich an den runden Esstisch gesetzt hatte, um ein Rezept auszuschreiben. Da sprang die Katze auf die Tischplatte und stürmte regelrecht auf mich zu. Als die Katze mein ganzes Blickfeld ausfüllte, schloss ich die Augen. Ich war auf etwas Warmes, Feuchtes gefasst, oder etwas Haariges.

Die Katze stupste ihre Nase vehement gegen meine Nase. Seitdem weiß ich, dass Katzennasen hart, trocken und lederartig sind, jedenfalls die Nasen von diesen asiatischen Katzen. Als ich meine Augen wieder öffnete, war das Tier verschwunden. Die Katzenbesitzerin fragte etwas spöttisch: "Na, wie war's?" Ich antwortete. ."Chatouillé." Es hat gekitzelt. Franzosen mögen Wortspiele.

Bei einem Katzenkenner erkundigte ich mich später, wie dieser Überfall durch das Tier zu interpretieren sei. Solche Nasenstüber seien die Aufforderung zu einer freundschaftlichen Beziehung, wurde mir erklärt.

Die Katzenbesitzerin brach allerdings unsere Beziehung bald darauf ab, weil ich nicht pünktlich genug zu den Besuchen käme. Als ich das hörte, musste ich lachen: Schwerkranke warten oft geduldig auf den Arzt. Für Menschen, denen eigentlich nichts fehlt - so wie es bei dieser Dame war - , ist die geringste Verzögerung unerträglich, zumal wenn außer dem Arztbesuch im Tagesablauf fast nichts passiert.

DR. MEd. Sibylle CouRnaC, MONTPELLIER -

\section{Was schmeckt nach Wachs?}

- Es war keine Frage, dass die akuten Rückenschmerzen bei dem Arbeiter mittleren Alters medikamentös behandelt werden sollten. Thema des Beratungsgespräches war vielmehr das Problem des Patienten mit der Tabletteneinnahme, und eine Injektion wolle er auch nicht. So verschrieb ich dem Patienten Diclofenac Zäpfchen.

Bei der Folgekonsultation berichtete er, er habe die Medikamente genommen und sie hätten auch gut gewirkt, lediglich der wachsartige Geschmack der länglichen Tabletten sei gewöhnungsbedürftig.

Dr. med. Albrecht Seller, Murg = 